\title{
Robotic Surgery for Colon and Rectal Cancer
}

\author{
Eun Jung Park ${ }^{1}$ - Seung Hyuk Baik ${ }^{1}$
}

Published online: 6 January 2016

(C) Springer Science+Business Media New York 2016

\begin{abstract}
Robotic surgery, used generally for colorectal cancer, has the advantages of a three-dimensional surgical view, steadiness, and seven degrees of robotic arms. However, there are disadvantages, such as a decreased sense of touch, extra time needed to dock the robotic cart, and high cost. Robotic surgery is performed using various techniques, with or without laparoscopic surgery. Because the results of this approach are reported to be similar to or less favorable than those of laparoscopic surgery, the learning curve for robotic colorectal surgery remains controversial. However, according to shortand long-term oncologic outcomes, robotic colorectal surgery is feasible and safe compared with conventional surgery. Advanced technologies in robotic surgery have resulted in favorable intraoperative and perioperative clinical outcomes as well as functional outcomes. As the technical advances in robotic surgery improve surgical performance as well as outcomes, it increasingly is being regarded as a treatment option for colorectal surgery. However, a multicenter, randomized clinical trial is needed to validate this approach.
\end{abstract}

Keywords Robotic surgery - Rectal cancer - Colon cancer . Oncologic outcomes $\cdot$ Total mesorectal excision $\cdot$ Learning curve

This article is part of the Topical Collection on Gastrointestinal Cancers

Seung Hyuk Baik

whitenoja@yuhs.ac

1 Division of Colon and Rectal Surgery, Department of Surgery, Yonsei University College of Medicine, Seoul 120-752,

Republic of Korea

\section{Introduction}

As the number of minimally invasive surgeries has increased, robotic surgery has gradually developed in various surgical fields. The first robot used in the surgical field was the automated endoscopic system for optimal positioning (AESOP; Computer Motion, Santa Barbara, CA), approved for clinical use by the US Food and Drug Administration in 1994. Later, the Zeus surgical system was invented but was used only as a surgical assistant. Today, the da Vinci ${ }^{\circledR}$ robotic system (Intuitive Surgical Inc., Sunnyvale, CA, USA) is the most popular surgical system for robotic surgery.

In colorectal surgery, the advanced technologies of robotic surgery have been allowed more meticulous dissection compared with conventional surgeries. Although laparoscopic surgery has advantages such as fast recovery times and favorable oncologic outcomes, laparoscopic total mesorectal excision (TME) for rectal cancer is a technically demanding procedure because of the narrow surgical field in the pelvic cavity. However, the ergonomic design and developed technologies of the robotic system can overcome these limitations.

The first robotic colorectal surgery was performed in 2001. Robotic colorectal surgery was reported in 2002 by Weber et al. [1] for benign disease and by Hashizume et al. [2] for malignant disease. D'Annibale et al. [3] performed 53 colorectal surgeries in 2003, and Pigazzi et al. [4] reported robotic TMEs for rectal cancer in 2006. Because of these developments in robotic surgery, it now is regarded as one of the treatment options for colorectal cancer. Therefore, in this article, we review the characteristics and overall clinical outcomes of robotic colorectal surgery. 


\section{Characteristics of Robotic Surgery: Advantages vs. Disadvantages}

Robotic surgery for colorectal cancer has several advantages over conventional surgery in performing precise dissection. It provides the surgeon with a three-dimensional surgical view, eliminates instrument tremor, and reduces movement of the robotic interface. Moreover, the tips of the robotic arms are ergonomically designed with an EndoWrist, which has seven degrees of freedom with $180^{\circ}$ articulation, which allow meticulous dissection of TME and aid in intraperitoneal suturing. The improved visual systems of robotic surgery also are useful in pelvic autonomic nerve preservation $[5,6]$. In addition, the surgeon can perform the operation ergonomically while seated. Pigazzi et al. [4] reported that this ergonomic design might result in less fatigue for the surgeon compared with conventional laparoscopic surgery.

However, robotic surgery has the disadvantage of providing less tactile sensation and tensile feedback to the surgeon compared with conventional surgeries, important drawbacks when manipulating tissue during an operation. In addition, the docking procedures of robotic carts are time consuming and require more assistants. Also, the robotic cart may be difficult to remove quickly if open conversion is needed because of urgent intraoperative bleeding. Collisions between robotic arms present another difficulty in using this technology to perform rectal cancer surgery.

Another important drawback regarding robotic surgery is its cost, which has limited its use universally. Park et al. [7••] reported that robotic surgery cost 2.34 times more than laparoscopic surgery in South Korea because robotic surgery is not covered by the health insurance system in that country. Whereas the total mean cost of laparoscopic surgery was $\$ 10,101.3 \pm 2804.8$ (US dollars) and that of robotic surgery was $\$ 12,742.5 \pm 3509.9$ (US dollars) $(P<0.001)$. Moreover, Baek and colleagues $[8,9]$ reported that total hospital charges after robotic rectal cancer surgery were $\$ 14,647$, higher than the $\$ 9978$ reported after laparoscopic surgery. Patients undergoing robotic surgery paid $\$ 11,540$ out of pocket, whereas those in the laparoscopic group paid \$3956. Although total hospital charges and the patient's bill for robotic surgery were higher than those for laparoscopic surgery, the costeffectiveness of robotic surgery was not demonstrated. Therefore, a need exists to assess its cost-effectiveness compared with functional and oncologic outcomes.

\section{Surgical Techniques: Hybrid vs. Totally Robotic Techniques}

Robotic colorectal surgery uses several techniques, such as the hybrid, totally robotic, reverse-hybrid, and natural orifice specimen extraction (NOSE) techniques. The hybrid technique comprises both laparoscopic and robotic procedures [10-12]. Laparoscopy is performed to ligate the inferior mesenteric vessels and to mobilize the splenic flexure. Then, pelvic dissection for TME is performed by the robotic system. Because this technique uses laparoscopic tools for splenic flexure mobilization, there is no need to change robotic carts when redocking. Placement of the working ports for the hybrid technique was shown in Fig. 1.

On the other hand, in totally robotic surgery, all procedures are performed by the robotic system. However, because splenic flexure colonic mobilization is limited after the robotic carts are docked, the position of the carts must be changed during surgery. Today, however, with advancements in port placement, this procedure may be performed as a single-stage or two-stage dissection [13-15]. Placement of the working ports for totally robotic surgery was shown in Figs. 2 and 3. Singlestage totally robotic surgery uses extra robotic ports to avoid the need to reposition the robotic cart. Some authors assert that the totally robotic technique allows more precise dissection of harvested lymph nodes and vessel ligation [13, 14]. However, others report that full splenic mobilization is difficult using a totally robotic approach with single docking $[12,16]$. In addition, Baik et al. [17•] reported that compared with the hybrid technique, totally robotic surgery had a longer operative time, lower numbers of harvested lymph nodes, and a higher rate of anastomotic leakage. However, although the hybrid and totally robotic techniques differ with regard to robotic procedures, both are performed universally with satisfactory feasibility and safety profiles [14]. With each new port placement design, robotic surgery can be performed by various techniques.

In the reverse-hybrid technique, the robotic interface is used during pelvic dissection, and then laparoscopy is performed for exploration [16]. Robotic dissection is performed to ligate the inferior mesenteric vessels and for TME; laparoscopy then is undertaken to mobilize the splenic flexure, using the same ports as those of the robotic portion. This approach is useful in radical lymphovascular and pelvic dissection, and there is no need for redocking or repositioning.

The NOSE technique differs from the other procedures described here with regard to transvaginal or transanal retrieval of specimens using robotic suturing techniques [18-20]. Choi et al. [19] reported their early experience with NOSE using robot-assisted laparoscopic rectal surgery in 2009. This technique is regarded as useful in rectal cancer surgery because it avoids traditional abdominal incisions while satisfying both feasibility and safety requirements. Because the NOSE technique was developed for easy specimen retrieval, patients must be selected carefully to eliminate those with bulky tumors. Possible contamination of the site during specimen retrieval may be prevented by using an endobag. Based on previous reports, robotic-assisted colorectal surgery with transanal or transvaginal specimen removal is considered safe and acceptable. 


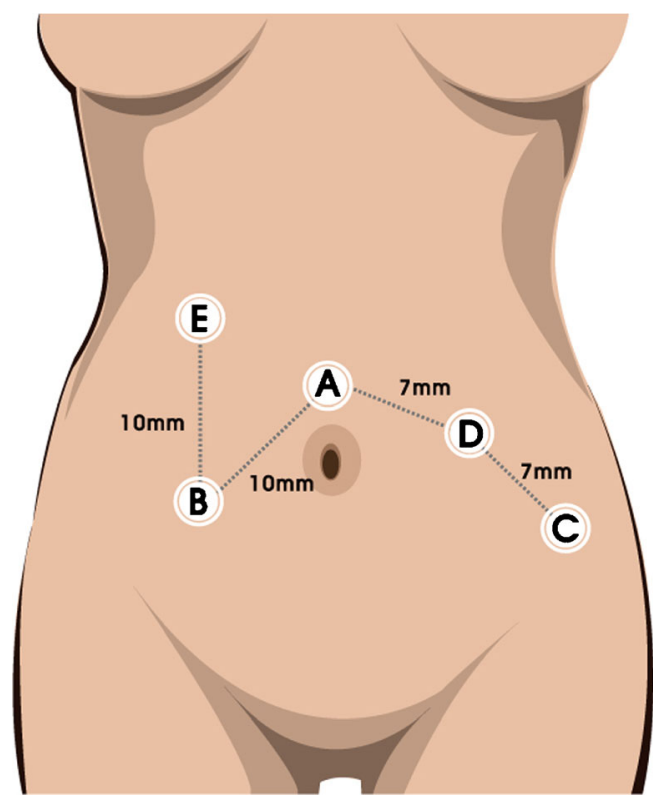

Fig. 1 Placement of the working ports for the hybrid technique. $A$ 12-mm camera port; $B$ 8-mm robot port; $C 8$-mm robot port, used for specimen delivery; $D$ 8-mm robot port; $E 11$-mm port for assistant

\section{Learning Curve for Robotic Surgery}

The learning curve for robotic colorectal surgery consists of multiple phases. According to Park et al. [21], it comprises three stages based on multidimensional statistical analyses, with most studies reporting an initial phase of 25 to 44 cases [21-23]. After completing the initial stage of the learning curve, surgeons enter the technical competency phase, after which they are ready for the challenge of more technically demanding cases. Based on these observations, recent studies have demonstrated that the learning curve for robotic colorectal surgery is composed of three phases [21-26].

Compared with the learning curve for laparoscopic colorectal surgery, it is still controversial whether that of robotic

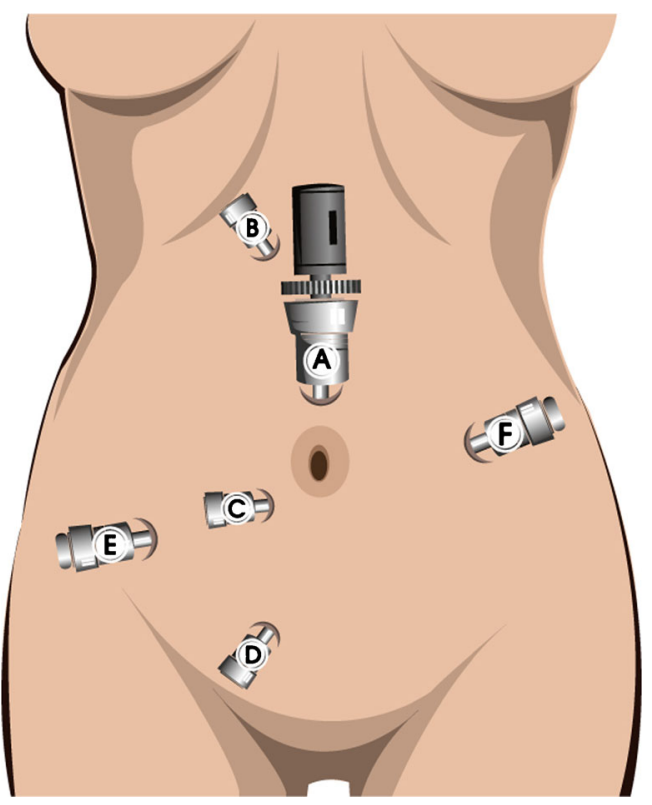

Fig. 3 Placement of the ports for single-stage totally robotic surgery. $A$ 12 -mm camera port, $B-F 8$-mm robot ports. The distance of $B$ and $C$ is $7-8 \mathrm{~cm}$ from the camera port $(A) . D$ is used for specimen delivery. $E$ is placed $5-6 \mathrm{~cm}$ apart from $C$ on the right anterior axillary line. $F$ is placed above the level of the umbilicus on the left mid-abdomen

surgery is shorter. Some studies reported that the learning curve for robotic surgery is shorter because the robotic system has overcome the technical difficulties associated with laparoscopy [12]. However, a recent study asserted that the learning curves for both methods are similar [24]. Although the robotic system has several technical advantages, the authors suggested that the achievement of TME and basic surgical skills for rectal cancer surgery might be more important than the surgical method used. Whereas laparoscopic surgery requires the cooperation of a surgical team, as well as the ability to manipulate rigid laparoscopic tools in the narrow pelvic cavity, robotic surgery requires the ability to set the robotic
Fig. 2 Placement of the working ports for two-stage totally robotic surgery. $A$ 12-mm camera port; $B, C$ 8-mm robot port; $D 12-\mathrm{mm}$ port for assistant; $E, F 8$-mm robot port. In the lateral phase, $B-D$ are used for working port. In the pelvic dissection, $B, E$, and $F$ are used for working port for TME
Lateral Phase

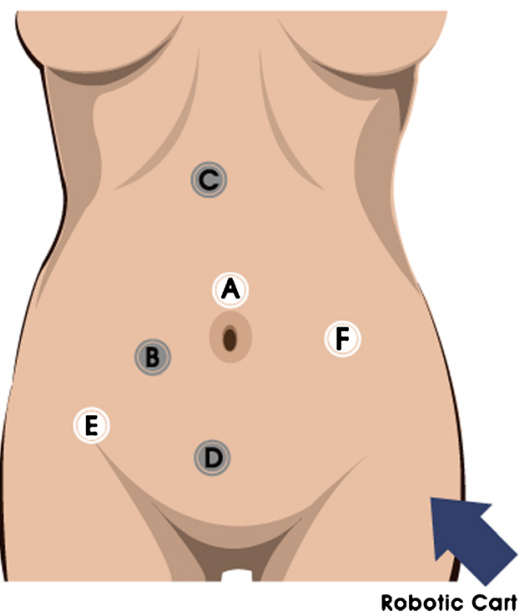

Pelvic Phase

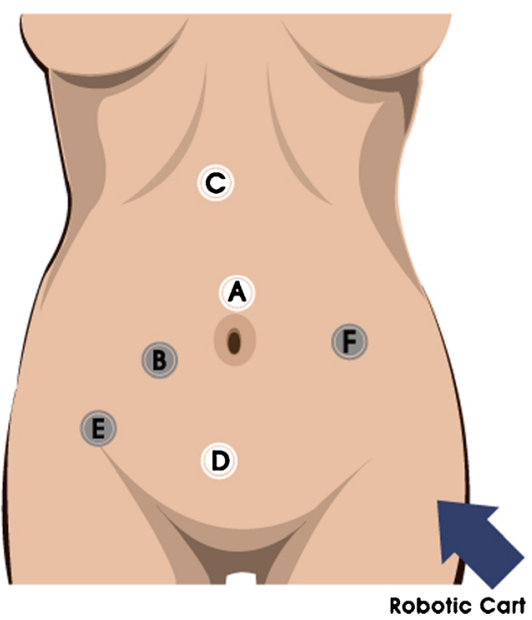


arms without collision as well as adaptation to the robotic system. Outcomes regarding the learning curve of laparoscopic versus robotic colorectal surgery are still under debate.

\section{Intraoperative and Perioperative Outcomes}

The short-term clinical outcomes of robotic colorectal surgery show it to be feasible and safe. Regarding intraoperative outcomes, most studies report a longer operative time for robotic versus laparoscopic surgery [20, 27-29]; however, some authors using the hybrid robotic technique reported that its operative time is similar to that of laparoscopic surgery [24, 30-32]. Differences between these methods might be a result of the initial learning curve for robotic surgery and the technical differences between the totally robotic and the hybrid techniques. Repositioning of robotic carts and redocking during totally robotic procedures may be obstacles in reducing surgical time.

With regard to estimated blood loss (EBL) during robotic surgery, it is less than or equal to EBL with laparoscopic surgery. A meta-analysis comparing robotic with laparoscopic TME found no significant differences in EBL between these procedures [32]. In most studies of robotic TME, EBL during robotic surgery was similar to EBL during laparoscopic surgery [28, 32-35].

Length of hospital stay (LOS) for patients undergoing robotic surgery was shorter than or similar to that of laparoscopic surgery patients [31], with a mean LOS of approximately 5 to 7 days. In addition, robotic surgery patients showed faster recoveries; the number of days to first passing of flatus and first diet was less than or similar to that in laparoscopic surgery patients [12, 27-31, 36].

The conversion rate for robotic TME is estimated to be 0 to $7.3 \%$ [36]. Although some studies found no difference in conversion rates between robotic and laparoscopic surgery $[12,27,30,37]$, other studies reported a lower rate for robotic surgery $[31,38]$. Conversion from robotic surgery was influenced by high body mass index, intraoperative bleeding, severe adhesions, technical difficulties regarding anatomy, and bowel dilatation. In addition, the space in which the robotic arms are manipulated in the abdominal cavity is limited, which also may affect the conversion rate [35].

With regard to complications, robotic surgery has shown lower or similar rates compared with laparoscopic surgery. In most studies, anastomotic leakage was a common postoperative complication, at a rate of 5 to $11 \%$. Baik et al. [31] reported that the rate of postoperative complications from robotic surgery was $5.4 \%$, compared with $19.3 \%$ for laparoscopic surgery $(P=0.025)$. Other studies, however, showed similar postoperative morbidity rates between robotic and laparoscopic surgery $[12,29,32,35,37]$. The technical advantages of robotic surgery, including precise dissection and advanced visual systems, have resulted in favorable perioperative outcomes. The lower or similar postoperative complication rates for robotic surgery may result in faster recovery and fewer days of hospital stay.

\section{Functional Outcomes: Urinary and Sexual Function}

Urinary and sexual dysfunction showed improvement and favorable outcomes after robotic rectal cancer surgery. Urogenital and sexual dysfunction due to injury to the pelvic autonomic nerves during dissection is assessed by the International Prostate Symptom Score (IPSS) and the International Index of Erectile Function (IIEF) questionnaires. D'Annibale et al. [38] reported that in both robotic and laparoscopic patient groups, IPSS significantly increased 1 month after surgery but normalized 1 year after surgery. Erectile function was reduced 1 month after surgery but was completely restored 1 year after surgery in the robotic group and was partially restored in the laparoscopic group. In comparing voiding and sexual function after TME in laparoscopic versus robotic surgical patients, Kim et al. [5] found similar results: IPSS increased 1 month after surgery but normalized at 3 months in the robotic group and at 6 months in the laparoscopic group. IIEF scores in the laparoscopic group normalized within 12 months, versus 6 months in the robotic group. In addition, Park et al. [39] reported earlier restoration of erectile function and significantly higher IIEF scores at 6 months in the robotic group versus the laparoscopy patients. Recent studies also demonstrate earlier and better recovery of voiding and sexual function in patients undergoing robotic rectal cancer surgery [39-42]. Although a large randomized, prospective study is needed, the technical advantages of robotic surgery in allowing more precise and meticulous dissection may be the reason for these favorable outcomes in urogenital and sexual function after surgery.

\section{Oncologic Outcomes: Short and Long Term}

To the best of our knowledge, the short-term and long-term oncologic outcomes of robotic surgery for rectal cancer are similar to those with laparoscopic surgery, even though robotic surgery uses more advanced technical methods.

Regarding short-term oncologic outcomes, Baek et al. reported that the 3-year overall survival (OS) rate after robotic colorectal surgery was $96.2 \%$, with a 3 -year disease-free survival (DFS) rate of $73.7 \%$ during a mean 20.2-month followup period. In addition, in a multicenter study of robotic TME, Pigazzi et al. [43] reported a 3-year OS of $97 \%$ and a 3-year DFS of $77.6 \%$ at a mean follow-up of 17.4 months; there was no local recurrence during the study period. In their analysis of pathologic outcomes of robotic surgery, Bianchi et al. [30] 
demonstrated that the number of harvested lymph nodes and the circumferential resection margin (CRM) did not differ from those achieved with laparoscopic surgery. Baik et al. [31] reported similar pathologic outcomes in patients undergoing robotic and laparoscopic surgery, although the specimens resected in the robotic group were more macroscopically complete, which along with proper harvesting of lymph nodes, is related to oncologic outcome [44].

Because better-quality or more complete resection specimens reflect the effectiveness of TME for rectal cancer, they represent important advantages of robotic surgery. For this reason, robotic surgery would be expected to result in better long-term oncologic outcomes. However, the long-term oncologic outcomes of robotic surgery for rectal cancer are similar to those of laparoscopic surgery. In analyzing the long-term oncologic outcomes of robotic rectal cancer surgery, Park et al. [7••] found no significant differences in 5-year OS, DFS, or local recurrence rates between patients treated with robotic and those treated with laparoscopic surgery for rectal cancer during a median follow-up period of 58 months. The 5year OS and DFS rates were 92.8 and $81.9 \%$ in the robotic surgery group, respectively. Local recurrence was similar in both the robotic and laparoscopic groups ( 2.3 and $1.2 \%$, respectively; $P=0.649$ ). In a case-matched study, Cho et al. [27] reported 5-year OS, DFS, and local recurrence rates of 93.1, 79.6, and $3.9 \%$, respectively, in patients undergoing TME using the totally robotic technique, which did not differ significantly from the rates observed in patients undergoing laparoscopic TME. Based on 200 consecutive cases of robotic surgery for rectal cancer, Hara et al. [45] reported a recurrence rate of $13.5 \%$, which included rates of $3.5 \%$ for local recurrence, $9.5 \%$ for distant metastasis, and $1.0 \%$ for both local and distant metastasis. Because long-term oncologic outcomes of robotic colorectal surgery are unknown and only single-center experience exists, these outcomes must be validated by randomized, multicenter clinical trials.

Now under way is a clinical trial known as Robotic versus Laparoscopic Resection for Rectal Cancer (ROLARR; NCT01736072) [46]. This study is an international, prospective, randomized, controlled, unblinded, superiority trial comparing robotic and laparoscopic surgery for rectal cancer. The results of this trial are expected to suggest level I evidence for robotic rectal cancer surgery.

\section{Robotic Surgery for Colon Cancer}

Robotic surgery for colon cancer, first reported in 2002, generally is performed for both right-sided and left-sided colon cancers. Robotic right colon resection with intracorporeal anastomosis was reported by Trastulli and coworkers [47, 48], with feasible and safe results. In colon cancer surgery, complete mesocolic excision (CME) is a concept similar to that of TME in rectal cancer. Because the colonic mesentery or mesocolon is responsible for the vascular and lymphatic drainage of the colon, previous studies considered CME to be oncologically beneficial [49]. As the robotic system has technical advantages in rectal cancer surgery, CME with central vascular ligation also can be performed by robotic surgery [ 48 , $50,51]$. Cho et al. [52] compared open and minimally invasive surgeries for modified CME in patients with right-sided colon cancer. Mathew et al. [48] reported a robotic right hemicolectomy with D3 lymphadenectomy and CME.

In addition, Lim et al. [53] reported robotic anterior resections for sigmoid colon cancer. Although the mean total operative time for robotic surgery was longer than that for laparoscopic surgery $(252.5 \pm 94.9$ vs. $217.6 \pm 70.7 \mathrm{~min}$, respectively; $P=0.016$ ), the mean time to soft diet and length of hospital stay were shorter for patients in the robotic surgery group versus those in the laparoscopic group. The perioperative and oncologic outcomes for robotic anterior resection were feasible.

Although it is more difficult to move in multiquadrant spaces in the abdomen with robotic than with laparoscopic surgery, robotic colon cancer surgery is performed universally nowadays.

\section{Advanced Techniques in Robotic Surgery}

Recently, robotic surgery has shown its feasibility for use in challenging cases, with studies reporting results of robotic extralevator abdominoperineal resection (ELAPR). Although performing dissection in a narrow pelvic cavity is difficult, the technical features of robotic surgery are useful in dissecting low rectal cancer or anal cancer for ELAPR [54-56]. In addition, Shin et al. [57] reported robotic pelvic exenteration for locally advanced rectal cancer invading the prostate and seminal vesicles, suggesting a potential role for robotic surgery in advanced rectal cancer. In selected cases, robotic procedures may be feasible for en bloc resection within adjacent involved organs.

Parallel to the development of robotic technology, the intraoperative near-infrared fluorescence (INIF) imaging system (Firefly ${ }^{\mathrm{TM}}$, Intuitive Surgical Inc.) has been used to identify vascular anatomy in real time during surgery. The INIF imaging system uses laser technology while activating indocyanine green dye intravenously. As surgeons switch from normal vision to INIF imaging on the surgical console, they can better identify vessel anatomy and lymph node dissection. Bae et al. $[58,59]$ reported that this technique made it easier to identify the left colic vessels as well as making lymph node dissection for robotic TME more precise.

Recently, robotic surgery using a single port site was reported. According to similar experience with the da Vinci Single-Site Port (Intuitive Surgical Inc.), reduced-port robotic 
surgery for left-sided colorectal cancer was reported using a robotic single-access platform [60]. Based on these efforts, robotic surgery has the potential to overcome the limitations of conventional surgeries.

\section{Conclusions}

Based on the short- and long-term outcomes of robotic surgery for colorectal cancer, this technique has a good feasibility and safety profile. The advanced technologies of robotic surgery have resulted in favorable intraoperative and perioperative clinical outcomes as well as functional outcomes. Because the technical advantages of robotic surgery have improved surgical performance in colorectal surgery, robotic surgery is now regarded as a treatment option for patients with this disease. To validate robotic colorectal surgery further, however, the results of a multicenter, randomized clinical trial are required.

Acknowledgments The authors thank MiSun Park (professional editor) for the English revision and Hae Won Shin (Medical Illustrator) for his help with the illustrations in this manuscript.

\section{Compliance with Ethical Standards}

Conflict of Interest Eun Jung Park and Seung Hyuk Baik declare that they have no conflict of interest.

Human and Animal Rights and Informed Consent This article does not contain any studies with human or animal subjects performed by any of the authors.

\section{References}

Papers of particular interest, published recently, have been highlighted as:

- Of importance

- Of major importance

1. Weber PA, Merola S, Wasielewski A, Ballantyne GH. Teleroboticassisted laparoscopic right and sigmoid colectomies for benign disease. Dis Colon Rectum. 2002;45(12):1689-94. doi:10.1097/01. dcr.0000037657.78153.a8. discussion 95-6.

2. Hashizume M, Shimada M, Tomikawa M, Ikeda Y, Takahashi I, Abe R, et al. Early experiences of endoscopic procedures in general surgery assisted by a computer-enhanced surgical system. Surg Endosc. 2002;16(8):1187-91. doi:10.1007/s004640080154.

3. D'Annibale A, Morpurgo E, Fiscon V, Trevisan P, Sovernigo G, Orsini C, et al. Robotic and laparoscopic surgery for treatment of colorectal diseases. Dis Colon Rectum. 2004;47(12):2162-8. doi: 10.1007/s10350-004-0711-z.

4. Pigazzi A, Ellenhorn JD, Ballantyne GH, Paz IB. Robotic-assisted laparoscopic low anterior resection with total mesorectal excision for rectal cancer. Surg Endosc. 2006;20(10):1521-5. doi:10.1007/ s00464-005-0855-5.
5. Kim JY, Kim NK, Lee KY, Hur H, Min BS, Kim JH. A comparative study of voiding and sexual function after total mesorectal excision with autonomic nerve preservation for rectal cancer: laparoscopic versus robotic surgery. Ann Surg Oncol. 2012;19(8):2485-93. doi: 10.1245/s10434-012-2262-1.

6. Baek SJ, Kim CH, Cho MS, Bae SU, Hur H, Min BS, et al. Robotic surgery for rectal cancer can overcome difficulties associated with pelvic anatomy. Surg Endosc. 2015;29(6):1419-24. doi:10.1007/ s00464-014-3818-x.

7.• Park EJ, Cho MS, Baek SJ, Hur H, Min BS, Baik SH, et al. Longterm oncologic outcomes of robotic low anterior resection for rectal cancer: a comparative study with laparoscopic surgery. Ann Surg. 2015;261(1):129-37. doi:10.1097/sla.0000000000000613. This article, the first to report the long-term oncologic outcomes of robotic low anterior resection for rectal cancer, discusses the oncologic perspectives and prognostic factors of robotic versus laparoscopic surgery for rectal cancer.

8. Kim CW, Baik SH, Roh YH, Kang J, Hur H, Min BS, et al. Costeffectiveness of robotic surgery for rectal cancer focusing on shortterm outcomes: a propensity score-matching analysis. Medicine (Baltimore). 2015;94(22), e823. doi:10.1097/md. 0000000000000823.

9. Baek SJ, Kim SH, Cho JS, Shin JW, Kim J. Robotic versus conventional laparoscopic surgery for rectal cancer: a cost analysis from a single institute in Korea. World J Surg. 2012;36(11):27229. doi:10.1007/s00268-012-1728-4.

10. Baik SH, Lee WJ, Rha KH, Kim NK, Sohn SK, Chi HS, et al. Robotic total mesorectal excision for rectal cancer using four robotic arms. Surg Endosc. 2008;22(3):792-7. doi:10.1007/s00464-007-9663-4.

11. Prasad LM, Marecik SJ, Blumetti J, Park JJ, Zimmern A, Abcarian $H$. Total mesorectal excision for rectal cancer: the potential advantage of robotic assistance. Dis Colon Rectum. 2010;53(12):1611-7.

12. Park JS, Choi G-S, Lim KH, Jang YS, Jun SH. Robotic-assisted versus laparoscopic surgery for low rectal cancer: case-matched analysis of short-term outcomes. Ann Surg Oncol. 2010;17(12): 3195-202.

13. Park YA, Kim JM, Kim SA, Min BS, Kim NK, Sohn SK, et al. Totally robotic surgery for rectal cancer: from splenic flexure to pelvic floor in one setup. Surg Endosc. 2010;24(3):715-20. doi: 10.1007/s00464-009-0656-3.

14. Choi DJ, Kim SH, Lee PJ, Kim J, Woo SU. Single-stage totally robotic dissection for rectal cancer surgery: technique and shortterm outcome in 50 consecutive patients. Dis Colon Rectum. 2009;52(11):1824-30. doi:10.1007/DCR.0b013e3181b13536.

15. Koh DC-S, Tsang CB-S, Kim S-H. A new application of the fourarm standard da Vinci ${ }^{\circledR}$ surgical system: totally robotic-assisted left-sided colon or rectal resection. Surg Endosc. 2011;25(6): 1945-52.

16. Park J, You YN, Schlette E, Nguyen S, Skibber JM, RodriguezBigas MA, et al. Reverse-hybrid robotic mesorectal excision for rectal cancer. Dis Colon Rectum. 2012;55(2):228.

17. Baik SH, Kim NK, Lim DR, Hur H, Min BS, Lee KY. Oncologic outcomes and perioperative clinicopathologic results after robotassisted tumor-specific mesorectal excision for rectal cancer. Ann Surg Oncol. 2013;20(8):2625-32. doi:10.1245/s10434-013-28958. This article discusses the oncologic and perioperative outcomes of robotic surgery for rectal cancer, highlighting the short-term oncologic outcomes of the hybrid versus the totally robotic technique.

18. Diana M, Perretta S, Wall J, Costantino F, Leroy J, Demartines N, et al. Transvaginal specimen extraction in colorectal surgery: current state of the art. Color Dis. 2011;13(6):e104-e11.

19. Choi G-S, Park IJ, Kang BM, Lim KH, Jun S-H. A novel approach of robotic-assisted anterior resection with transanal or transvaginal retrieval of the specimen for colorectal cancer. Surg Endosc. 2009;23(12):2831-5. 
20. Park JS, Choi G-S, Lim KH, Jang YS, Jun SH. S052: a comparison of robot-assisted, laparoscopic, and open surgery in the treatment of rectal cancer. Surg Endosc. 2011;25(1):240-8.

21. Park EJ, Kim CW, Cho MS, Baik SH, Kim DW, Min BS, et al. Multidimensional analyses of the learning curve of robotic low anterior resection for rectal cancer: 3-phase learning process comparison. Surg Endosc. 2014;28(10):2821-31. doi:10.1007/s00464014-3569-8.

22. Yamaguchi T, Kinugasa Y, Shiomi A, Sato S, Yamakawa Y, Kagawa $\mathrm{H}$, et al. Learning curve for robotic-assisted surgery for rectal cancer: use of the cumulative sum method. Surg Endosc. 2015;29(7):1679-85. doi:10.1007/s00464-014-3855-5.

23. Kim HJ, Choi GS, Park JS, Park SY. Multidimensional analysis of the learning curve for robotic total mesorectal excision for rectal cancer: lessons from a single surgeon's experience. Dis Colon Rectum. 2014;57(9):1066-74. doi:10.1097/dcr. 0000000000000174.

24. Park EJ, Kim CW, Cho MS, Kim DW, Min BS, Baik SH, et al. Is the learning curve of robotic low anterior resection shorter than laparoscopic low anterior resection for rectal cancer?: a comparative analysis of clinicopathologic outcomes between robotic and laparoscopic surgeries. Medicine (Baltimore). 2014;93(25), e109. doi: 10.1097/md.0000000000000109.

25. Sng KK, Hara M, Shin JW, Yoo BE, Yang KS, Kim SH. The multiphasic learning curve for robot-assisted rectal surgery. Surg Endosc. 2013;27(9):3297-307. doi:10.1007/s00464-013-2909-4.

26. Bokhari MB, Patel CB, Ramos-Valadez DI, Ragupathi M, Haas EM. Learning curve for robotic-assisted laparoscopic colorectal surgery. Surg Endosc. 2011;25(3):855-60. doi:10.1007/s00464010-1281-x.

27. Cho MS, Baek SJ, Hur H, Min BS, Baik SH, Lee KY, et al. Short and long-term outcomes of robotic versus laparoscopic total mesorectal excision for rectal cancer: a case-matched retrospective study. Medicine (Baltimore). 2015;94(11), e522. doi:10.1097/md. 0000000000000522.

28. Park SY, Choi GS, Park JS, Kim HJ, Ryuk JP. Short-term clinical outcome of robot-assisted intersphincteric resection for low rectal cancer: a retrospective comparison with conventional laparoscopy. Surg Endosc. 2013;27(1):48-55. doi:10.1007/s00464-012-2405-2.

29. Yoo BE, Cho JS, Shin JW, Lee DW, Kwak JM, Kim J, et al. Robotic versus laparoscopic intersphincteric resection for low rectal cancer: comparison of the operative, oncological, and functional outcomes. Ann Surg Oncol. 2015;22(4):1219-25. doi:10.1245/s10434-0144177-5.

30. Bianchi PP, Ceriani C, Locatelli A, Spinoglio G, Zampino MG, Sonzogni A, et al. Robotic versus laparoscopic total mesorectal excision for rectal cancer: a comparative analysis of oncological safety and short-term outcomes. Surg Endosc. 2010;24(11):288894. doi:10.1007/s00464-010-1134-7.

31. Baik SH, Kwon HY, Kim JS, Hur H, Sohn SK, Cho CH, et al. Robotic versus laparoscopic low anterior resection of rectal cancer: short-term outcome of a prospective comparative study. Ann Surg Oncol. 2009;16(6):1480-7. doi:10.1245/s10434-009-0435-3.

32. Xiong B, Ma L, Zhang C, Cheng Y. Robotic versus laparoscopic total mesorectal excision for rectal cancer: a meta-analysis. J Surg Res. 2014;188(2):404-14. doi:10.1016/j.jss.2014.01.027.

33. Wong MT, Meurette G, Rigaud J, Regenet N, Lehur PA. Robotic versus laparoscopic rectopexy for complex rectocele: a prospective comparison of short-term outcomes. Dis Colon Rectum. 2011;54(3):342-6. doi:10.1007/DCR.0b013e3181f4737e.

34. Park JS, Choi GS, Park SY, Kim HJ, Ryuk JP. Randomized clinical trial of robot-assisted versus standard laparoscopic right colectomy. Br J Surg. 2012;99(9):1219-26. doi:10.1002/bjs.8841.

35. Kim CW, Kim CH, Baik SH. Outcomes of robotic-assisted colorectal surgery compared with laparoscopic and open surgery: a systematic review. J Gastrointest Surg. 2014;18(4):816-30. doi: 10.1007/s11605-014-2469-5.

36. Kim N-K, Kang J. Optimal total mesorectal excision for rectal cancer: the role of robotic surgery from an expert's view. J Korean Soc Coloproctol. 2010;26(6):377-87.

37. Baek JH, Pastor C, Pigazzi A. Robotic and laparoscopic total mesorectal excision for rectal cancer: a case-matched study. Surg Endosc. 2011;25(2):521-5. doi:10.1007/s00464-010-1204-x.

38. D'Annibale A, Pernazza G, Monsellato I, Pende V, Lucandri G, Mazzocchi P, et al. Total mesorectal excision: a comparison of oncological and functional outcomes between robotic and laparoscopic surgery for rectal cancer. Surg Endosc. 2013;27(6):1887-95. doi:10.1007/s00464-012-2731-4.

39. Park SY, Choi GS, Park JS, Kim HJ, Ryuk JP, Yun SH. Urinary and erectile function in men after total mesorectal excision by laparoscopic or robot-assisted methods for the treatment of rectal cancer: a case-matched comparison. World J Surg. 2014;38(7):1834-42. doi: 10.1007/s00268-013-2419-5.

40. Morelli L, Ceccarelli C, Di Franco G, Guadagni S, Palmeri M, Caprili $\mathrm{G}$ et al. Sexual and urinary functions after robot-assisted versus pure laparoscopic total mesorectal excision for rectal cancer. Int J Colorectal Dis. 2015.

41. Kim NK, Kim YW, Cho MS. Total mesorectal excision for rectal cancer with emphasis on pelvic autonomic nerve preservation: expert technical tips for robotic surgery. Surg Oncol. 2015.

42. Broholm M, Pommergaard HC, Gogenur I. Possible benefits of robot-assisted rectal cancer surgery regarding urological and sexual dysfunction: a systematic review and meta-analysis. Color Dis. 2015;17(5):375-81. doi:10.1111/codi.12872.

43. Pigazzi A, Luca F, Patriti A, Valvo M, Ceccarelli G, Casciola L, et al. Multicentric study on robotic tumor-specific mesorectal excision for the treatment of rectal cancer. Ann Surg Oncol. 2010;17(6): 1614-20.

44. Nagtegaal ID, van de Velde CJ, van der Worp E, Kapiteijn E, Quirke P, van Krieken JH. Macroscopic evaluation of rectal cancer resection specimen: clinical significance of the pathologist in quality control. J Clin Oncol. 2002;20(7):1729-34.

45. Hara M, Sng K, Yoo BE, Shin JW, Lee DW, Kim SH. Roboticassisted surgery for rectal adenocarcinoma: short-term and midterm outcomes from 200 consecutive cases at a single institution. Dis Colon Rectum. 2014;57(5):570-7. doi:10.1097/dcr. 0000000000000088 .

46. Collinson FJ, Jayne DG, Pigazzi A, Tsang C, Barrie JM, Edlin R, et al. An international, multicentre, prospective, randomised, controlled, unblinded, parallel-group trial of robotic-assisted versus standard laparoscopic surgery for the curative treatment of rectal cancer. Int J Color Dis. 2012;27(2):233-41. doi:10.1007/s00384011-1313-6.

47. Trastulli S, Desiderio J, Farinacci F, Ricci F, Listorti C, Cirocchi R, et al. Robotic right colectomy for cancer with intracorporeal anastomosis: short-term outcomes from a single institution. Int J Color Dis. 2013;28(6):807-14.

48. Mathew R, Kim S. Robotic right hemicolectomy with D3 lymphadenectomy and complete mesocolic excision: technical detail. OA Rob Surg. 2013;1(6)

49. West NP, Hohenberger W, Weber K, Perrakis A, Finan PJ, Quirke P. Complete mesocolic excision with central vascular ligation produces an oncologically superior specimen compared with standard surgery for carcinoma of the colon. J Clin Oncol. 2010;28(2):2728. doi:10.1200/jco.2009.24.1448.

50. Hohenberger W, Weber K, Matzel K, Papadopoulos T, Merkel S. Standardized surgery for colonic cancer: complete mesocolic excision and central ligation - technical notes and outcome. Color Dis. 2009;11(4):354-64. doi:10.1111/j.1463-1318.2008.01735.x. discussion 64-5. 
51. Pappou EP, Weiser MR. Robotic colonic resection. Journal of Surgical Oncology. 2015

52. Cho MS, Baek SJ, Hur H, Min BS, Baik SH, Kim NK. Modified complete mesocolic excision with central vascular ligation for the treatment of right-sided colon cancer: long-term outcomes and prognostic factors. Ann Surg. 2015;261(4):708-15.

53. Lim DR, Min BS, Kim MS, Alasari S, Kim G, Hur H, et al. Robotic versus laparoscopic anterior resection of sigmoid colon cancer: comparative study of long-term oncologic outcomes. Surg Endosc. 2013;27(4):1379-85. doi:10.1007/s00464-012-2619-3.

54. Park EJ, Baik SH, Kang J, Hur H, Min BS, Lee KY et al. Short-term outcomes of the modified extralevator abdominoperineal resection for low rectal cancer (with videos). Surg Endosc. 2015:1-11.

55. Bae SU, Saklani AP, Hur H, Min BS, Baik SH, Kim NK. Robotic interface for transabdominal division of the levators and pelvic floor reconstruction in abdominoperineal resection: a case report and technical description. Int J Med Robot. 2014. doi:10.1002/rcs.1624.
56. Marecik SJ, Zawadzki M, Desouza AL, Park JJ, Abcarian H, Prasad LM. Robotic cylindrical abdominoperineal resection with transabdominal levator transection. Dis Colon Rectum. 2011;54(10):1320-5. doi:10.1097/DCR.0b013e31822720a2.

57. Shin JW, Kim J, Kwak JM, Hara M, Cheon J, Kang SH, et al. First report: robotic pelvic exenteration for locally advanced rectal cancer. Color Dis. 2014;16(1):O9-14. doi:10.1111/codi.12446.

58. Bae SU, Min BS, Kim NK. Robotic low ligation of the inferior mesenteric artery for rectal cancer using the Firefly technique. Yonsei Med J. 2015;56(4):1028-35. doi:10.3349/ymj.2015.56.4.1028.

59. Bae SU, Baek SJ, Hur H, Baik SH, Kim NK, Min BS. Intraoperative near infrared fluorescence imaging in robotic low anterior resection: three case reports. Yonsei Med J. 2013;54(4): 1066-9. doi:10.3349/ymj.2013.54.4.1066.

60. Bae SU, Jeong WK, Bae OS, Baek SK. Reduced-port robotic anterior resection for left-sided colon cancer using the da Vinci singlesite platform. Int J Med Robot. 2015. doi:10.1002/rcs.1677. 